\title{
PENGGUNAAN METODE CUTTING PLANE UNTUK MENYELESAIKAN MINIMUM SPANNING TREE DENGAN KENDALA BOBOT PADA GRAF $K_{n}$
}

\author{
Dewi Suhika $^{1)}$, Wamiliana ${ }^{2)}$ \\ ${ }^{1)}$ Institut Teknologi Sumatera, ${ }^{2)}$ Universitas Lampung \\ E-mail: dewi.suhika@ma.itera.ac.id ${ }^{1)}$,wamiliana.1963@fmipa.unila.ac.id ${ }^{2)}$
}

\begin{abstract}
This study aims to determine the minimum spanning tree of a complete graph $K_{n}$ with weight constraints and completion using the cutting plane method. The cutting plane method is one of the algorithms included in the exact method. This algorithm works by reducing the solution area so that it becomes narrower. As a result, the feasible solutions that will be investigated become less and less. This is because the cutting plane method works based on the optimal linear programming solution of relaxation solved by the simplex method. In this paper we give illustration of the algorithm applied for two cases, one for $K_{4}$ and one for $\mathrm{K}_{5}$
\end{abstract}

Keywords: complete graph, cutting plane method, minimum spanning tree, tree.

\section{PENDAHULUAN}

Teori graf merupakan bagian ilmu matematika yang memiliki banyak terapannya sampai saat ini. Graf digunakan untuk merepresentasikan objek-objek diskrit dan hubungannya antara objek-objek tersebut. Representasi visual dari graf adalah dengan menyatakan objek sebagai vertex (titik/simpul), sedangkan hubungan antara objek dinyatakan dengan edge (garis/sisi) (Deo, 1989).

Salah satu contoh aplikasi graf dalam kehidupan sehari-hari adalah jaringan persahabatan pada facebook yang dapat direpresentasikan dengan graf, dimana kumpulan vertex adalah para pengguna facebook dan sisi-sisi yaitu hubungan antar pengguna satu dengan yang lainnya. Selain itu graf juga dapat diaplikasikan untuk menentukan jarak terpendek, waktu tempuh tersingkat, ongkos termurah antar dua buah kota, pembangunan jembatan, bagan alir pendaftaran mahasiswa baru, rangkaian listrik, jarak antar kota pada peta dan lain sebagainya (Nurbaiti dan Wahyuni, 2015).
Graf terhubung yang tidak memuat sirkuit disebut tree. Diantara sekian banyak konsep dalam teori graf, konsep tree mungkin merupakan salah satu konsep yang paling penting karena terapannya yang luas dalam berbagai ilmu. Banyak terapan, baik dalam bidang ilmu komputer maupun di luar bidang ilmu komputer, yang telah mengkaji tree secara intensif sebagai objek matematika. Dalam kehidupan sehari-hari, tree dapat digunakan untuk merepresentasikan hirarkhi. Misalnya, pohon silsilah keluarga, struktur organisasi, dan lain-lain (Munir, 2012).

Suatu subgraf $G$ yang merupakan tree dan memuat semua titik di $G$ disebut spanning tree (Siang, 2009). Misalkan $G=(V, E)$ adalah graf berbobot, maka bobot spanning tree $T=\left(V_{1}, E_{1}\right)$ dari $G$ didefinisikan sebagai jumlah bobot semua sisi di $T$. Spanning tree yang berbeda mungkin mempunyai bobot yang berbeda pula. Diantara semua spanning tree di $G$, spanning tree yang berbobot minimum dinamakan minimum spaning tree (MST) (Munir, 2012). 
Minimum spanning tree mempunyai terapan yang luas dalam dunia nyata. Misalkan pemerintah akan membangun jalur rel kereta api yang menghubungkan sejumlah kota. Membangun jalur kereta api biayanya tidak murah, karena itu pembangunan jalur ini tidak perlu menghubungkan langsung dua buah kota, tetapi cukup membangun jalur kereta seperti spanning tree. Karena di dalam sebuah graf mungkin saja terdapat lebih dari satu spanning tree, maka harus dicari spanning tree yang mempunyai jarak terpendek, dengan kata lain harus dicari minimum spanning tree.

Pada penelitian ini akan digunakan metode cutting plane untuk menentukan minimum spanning tree pada grap lengkap $K_{n}$ dengan kendala bobot. Metode cutting plane merupakan salah satu algoritma yang termasuk kedalam metode eksak. Algoritma ini bekerja dengan cara mereduksi daerah solusi sehingga menjadi lebih sempit. Akibatnya, solusi layak yang akan diinvestigasi menjadi semakin sedikit sehingga dihasilkan solusi yang optimal. Solusi optimal merupakan suatu hasil yang mencerminkan tercapainya sasaran tertentu yang paling baik diantara alternatif-alternatif yang mungkin (Subagyo, Asri, dan Handoko, 2009).

Pada penelitian ini akan didiskusikan metode cutting plane untuk menyelesaikan masalah minimum spanning tree dengan kendala bobot, khususnya pada graf lengkap $K_{4}$ dan $K_{5}$. Alasan pemilihan hanya pada graf $K_{4}$ dan $K_{5}$ karena untuk $n \geq 6$ kendalanya mencapai lebih dari seribu pertidaksamaan. Untuk $K_{6}$ kendala yang terdiri dari 2.362 pertidaksamaan. Sehingga tidak mudah dalam menentukan pertidaksaksamaan untuk $n \geq 6$ karena pertidaksamaannya mencapai lebih dari seribu.
Tujuan penelitian ini adalah menentukan minimum spanning tree pada graf $K_{4}$ dan $K_{5}$ dengan menggunakan metode cutting plane.

\section{METODE PENELITIAN}

Metode yang digunakan dalam penelitian ini adalah kajian literatur seperti buku-buku penunjang, internet, dan jurnal yang berhubungan dengan minimum spanning tree (MST) dan algorima cutting plane. Adapun tahaptahap yang dilakukan dalam penelitian ini adalah sebagai berikut

1. Menginventaris literatur yang berhubungan dengan penelitian.

2. Mempelajari dan memahami definisi-definisi serta istilahistilah yang saling mendukung.

3. Mengunakan definisi-definisi dan istilah-istilah sebagai acuan untuk melakukan penelitian.

Secara umum tahapan penelitian ini diuraikan pada langkah-langkah sebagai berikut:

1. Menentukan cost dan weight pada grap lengkap $K_{4}$ dan $K_{5}$.

2. Menentukan minimum spanning tree dari graf $K_{4}$ dan $K_{5}$ yang memuat cost dan weight dengan menggunakan metode cutting plane. Langkah-langkah metode cutting plane adalah sebagai berikut (Bronson, 1996).

a. Menentukan tabel optimal dengan menggunakan metode simpleks untuk menyelesaikan linear programming relaxation (LPR) dari Integer Program (IP). Jika semua variabel didalam solusi optimal bemifai integer, maka telah didapatkan solusi optimal IP. Sebaliknya jika tidak maka ke Langkah 2. 
b. Lihat tabel simpleks pada RHS (right-hand side), pilih salah satu variabel yang merupakan pecahan.

i. Tulis baris yang menghasilkan pecahan sebagai suatu persamaan. Nyatakan persamaan tersebut sebagai penjumlahan dari $\lfloor x\rfloor$ dalam bentuk $\lfloor x\rfloor+f$, dengan $0 \leq f<1$.

ii. Tulis kembali baris yang menghasilkan dan mengelompokan nilai/konstanta yang bemilai integer disebelah kiri dan nilai pecahan disebelah kanan.

Semua nilai/ konstanta yang bernilai integer sama dengan semua nilai pecahan. Kemudian buat suatu pertidaksamaan dengan cara mengambil ruas kanan kurang dari sama dengan nol. Pertidaksamaan ini disebut cut.

c. Jika semua variabel bernilai integer di dalam solusi optimal maka telah didapatkan solusi optimal IP. Sebaliknya jika tidak kembali ke Langkah 2.

3. Setelah itu cut edge pada graf $K_{4}$ dan $K_{5}$ dari persamaan baru yang diperoleh dari metode cutting plane sampai terbentuk minimum spanning tree.

Diagram alir untuk metode ini adalah sebagai berikut

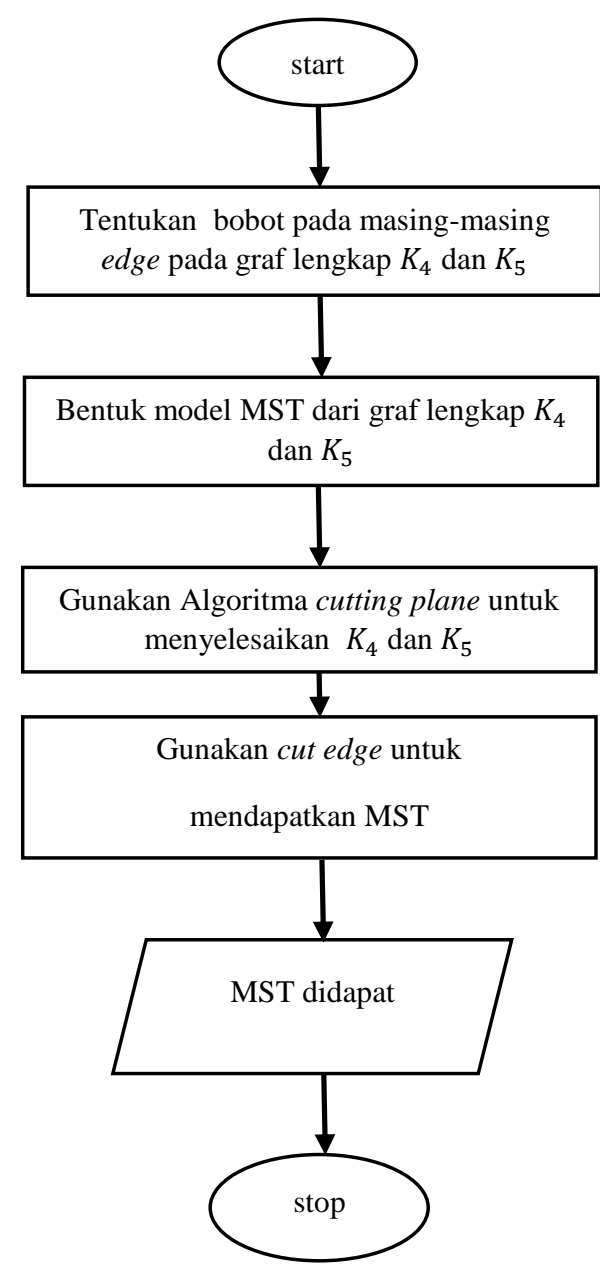

Gambar 1. Diagram alir penelitian

\section{HASIL PENELITIAN DAN PEMBAHASAN}

Pada bab ini akan dibahas tentang minimum spanning tree dengan kendala bobot dan aplikasinya pada graf Iengkap $K_{4}$ dan $K_{5}$. Untuk menentukan minimum spanning tree (MST) dari graf lengkap khususnya $K_{4}$ dan $K_{5}$ akan digunakan metode cutting plane. Metode cutting plane digunakan untuk memotong edge pada graf $K_{4}$ dan $K_{5}$ yang memuat bobot pada edge-nya sampai dihasilkan MST.

\section{Minimum Spanning Tree (MST) dengan Kendala Bobot}

Diberikan MST dengan kendala bobot sebagai berikut, 


$\mathrm{OPT}_{(4.1)}:=\quad \min \quad \sum_{c \in E} c_{e} x_{e}$

Dengan kendala

$\sum_{c \in S} w_{e} x_{e} \leq W$

$\sum_{c \in E} x_{e} \leq|S|-1$, untuk setiap

$S \in \mathcal{S}$ dengan $2 \leq|S| \leq n-1$

(4.3)

$\sum_{c \in E} x_{e}=n-1$

$x_{e} \in\{0,1\}$

(Henn, 2007)

Keterangan

$$
\begin{aligned}
& x_{c}= \\
& \left\{\begin{array}{l}
1, \text { jika tree memuat edge e } \\
0, \text { selainnya }
\end{array}\right.
\end{aligned}
$$

$c_{e}$ merupakan cost (biaya) dari semua edge $(e)$ yang terdapat pada graf dan $w_{e}$ adalah weight dari semua edge yang terdapat pada graf. $\mathcal{S}$ merupakan himpunan semua subgraf dari $G$, dan $S$ adalah jumlah edge yang terdapat pada subgraf dari $G$.

Persamaan (4.2) adalah bobot semua edge yang tidak lebih dari maksimal bobot yang telah ditentukan. $W$ adalah maksimal bobot yang ditentukan. Persamaan (4.3) memastikan bahwa subgraf tidak memuat sirkuit $2 \leq|S| \leq$ $n-1$ dan persamaan (4.4) menyatakan bahwa semua vertex harus terhubung.

Aplikasi dari masalah MST ini adalah misalkan pemerintah ingin membangun jalan yang menghubungkan lima kota dengan total jarak maksimal $200 \mathrm{~km}$, karena di setiap kota mungkin mempunyai lebih dari satu rute untuk menghubungkan ke kota lain maka harus dicari jarak minimumnya supaya tidak melebihi jarak maksimal, sehingga biaya yang dikeluarkan untuk membangun jalan tersebut minimum.
Oleh karena itu, cukup membangun jalan yang menghubungkan lima kota seperti spanning tree yang mempunyai jarak minimum atau dengan kata lain harus dicari minimum spanning tree.

Dalam pembahasan ini hanya akan didiskusikan MST dengan kendala bobot yang diaplikasikan pada graf lengkap $K_{4}$ dan $K_{5}$. Alasan pemilihan $K_{4}$ dan $K_{5}$ ini adalah karena untuk $n \geq 6$ kendalanya mencapai lebih dari seribu pertidaksamaan.

Berikut ini contoh Minimum Spanning Tree pada graf lengkap $K_{4}$ dengan kendala bobot dan penyelesaiannya dengan menggunakan metode cutting plane, dengan bobot maksimalnya adalah kurang dari sama dengan 16.

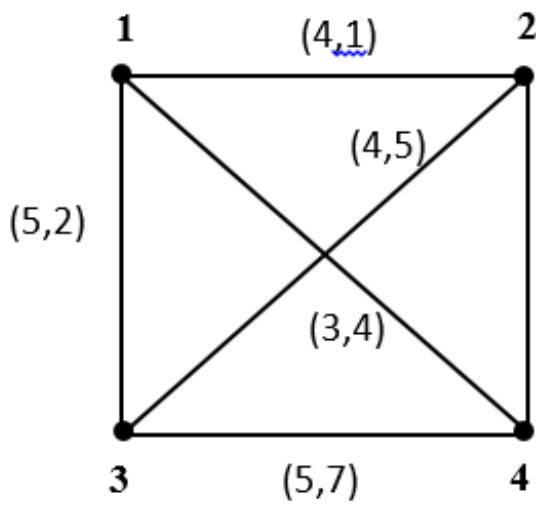

Gambar 2. Graf lengkap $K_{4}$

Fungsi tujuan

$\operatorname{Min} Z=4 x_{12}+5 x_{13}+4 x_{14}+3 x_{23}+$ $x_{24}+5 x_{34}$

dengan kendala

$$
\begin{aligned}
& x_{12}+2 x_{13}+5 x_{14}+4 x_{23}+4 x_{24}+ \\
& 7 x_{34} \leq 16 \\
& x_{12}+x_{13}+x_{14} \leq 3 \\
& x_{12}+x_{13}+x_{24} \leq 3 \\
& x_{12}+x_{13}+x_{34} \leq 3 \\
& x_{12}+x_{14}+x_{34} \leq 3 \\
& x_{12}+x_{23}+x_{24} \leq 3
\end{aligned}
$$


ISSN 2089-8703 (Print) Vol. 7, No. 1 (2018)

ISSN 2442-5419 (Online)

$$
\begin{aligned}
& x_{12}+x_{23}+x_{34} \leq 3 \\
& x_{12}+x_{24}+x_{34} \leq 3 \\
& x_{13}+x_{14}+x_{24} \leq 3 \\
& x_{13}+x_{23}+x_{24} \leq 3 \\
& x_{13}+x_{23}+x_{34} \leq 3 \\
& x_{13}+x_{24}+x_{34} \leq 3 \\
& x_{14}+x_{23}+x_{34} \leq 3 \\
& x_{14}+x_{24}+x_{34} \leq 3 \\
& x_{12}+x_{14}+x_{23} \leq 3 \\
& x_{13}+x_{14}+x_{23} \leq 3 \\
& x_{14}+x_{23}+x_{24} \leq 3 \\
& x_{12}+x_{13} \leq 2 \\
& x_{12}+x_{14} \leq 2 \\
& x_{12}+x_{23} \leq 2 \\
& x_{12}+x_{24} \leq 2 \\
& x_{13}+x_{14} \leq 2 \\
& x_{13}+x_{24} \leq 2 \\
& x_{13}+x_{34} \leq 2 \\
& x_{14}+x_{24} \leq 2 \\
& x_{14}+x_{34} \leq 2 \\
& x_{23}+x_{24} \leq 2 \\
& x_{23}+x_{34} \leq 2 \\
& x_{24}+x_{34} \leq 2 \\
& x_{12} \leq 1 \\
& x_{13} \leq 1 \\
& x_{14} \leq 1 \\
& x_{23} \leq 1 \\
& x_{24} \leq 1 \\
& x_{12}+x_{13}+x_{14}+x_{23}+x_{24}+x_{34}=3
\end{aligned}
$$

$$
x_{12}, x_{13}, x_{14}, x_{23}, x_{24}, x_{34} \in\{0,1\}
$$

Penyelesaian dengan menggunakan metode cutting plane

1. Relaks IP menjadi LPR (Linear Programming Relaksasi) dan gunakan simpleks untuk menyelesaikan LPR. Berikut langkah-langkah metode simpleks (Wamiliana, 2015):

a. Mengubah fungsi tujuan dan batasan-batasan menjadi kendala ke-36 kesamaan (=), maka mengubah batasan $x_{12}+x_{13}+x_{14}+x_{23}+$ $x_{24}+x_{34}=3$.

Jika diselesaikan dengan metode simpleks harus ditambahkan satu variabel lagi, karena pada batasan itu belum ada variabel yang merupakan variabel dasar (basic variable) pada tabel pertama, dan variabel tersebut adalah variabel yang bersifat tidak negative $\left(S_{36}\right)$, sehingga persamaan tersebut menjadi

$x_{12}+x_{13}+x_{14}+x_{23}+$ $x_{24}+x_{34}+S_{36}=3$ Karena adanya variabel $S_{36}$ ini maka fungsi tujuan harus disesuaikan dengan menambah bilangan $M$ sehingga fungsi tujuan yang baru menjadi

$Z=4 x_{12}+5 x_{13}+4 x_{14}+$ $3 x_{23}+x_{24}+5 x_{34}-M S_{36}$ Bilangan $M$ sangat besar tetapi berhingga, sehingga nilai $Z$ maksimum diperoleh apabila nilai $S_{36}=0$. Fungs tujuannya diubah menjadi fungsi implisit sebagai berikut

$$
\begin{gathered}
Z-4 x_{12}-5 x_{13}-4 x_{14} \\
-3 x_{23} \\
-x_{24}-5 x_{34}+M S_{36}=0
\end{gathered}
$$


ISSN 2089-8703 (Print) Vol. 7, No. 1 (2018)

ISSN 2442-5419 (Online)

Agar persamaan tujuan di atas dapat digunakan dalam metode tabel simpleks maka diubah dengan menguranginya dengan $M$ dikalikan baris batasan yang bersangkutan, sehingga fungsi tersebut setelah diubah akan menjadi sebagai berikut

Maks: $-\mathrm{Z}=-(M+$ 4) $x_{12}-$

$$
\begin{aligned}
& (M+5) x_{13}- \\
& (M+4) x_{14}- \\
& (M+3) x_{23}- \\
& (M+1) x_{24}- \\
& (M+5) x_{34}=-3 M
\end{aligned}
$$

dengan kendala

$$
\begin{aligned}
& x_{12}+2 x_{13}+5 x_{14}+4 x_{23}+ \\
& 4 x_{24}+7 x_{34}+S_{1}=16 \\
& x_{12}+x_{13}+x_{14}+S_{2}=3 \\
& x_{12}+x_{13}+x_{24}+S_{3}=3 \\
& x_{12}+x_{13}+x_{34}+S_{4}=3 \\
& x_{12}+x_{13}+x_{34}+S_{5}=3 \\
& x_{12}+x_{23}+x_{24}+S_{6}=3 \\
& x_{12}+x_{23}+x_{34}+S_{7}=3 \\
& x_{12}+x_{24}+x_{34}+S_{8}=3 \\
& x_{13}+x_{14}+x_{24}+S_{9}=3 \\
& x_{13}+x_{23}+x_{24}+S_{10}=3 \\
& x_{13}+x_{23}+x_{34}+S_{11}=3 \\
& x_{13}+x_{24}+x_{34}+S_{12}=3 \\
& x_{14}+x_{23}+x_{34}+S_{13}=3 \\
& x_{14}+x_{24}+x_{34}+S_{14}=3 \\
& x_{12}+x_{14}+x_{23}+S_{15}=3 \\
& x_{13}+x_{14}+x_{23}+S_{16}=3 \\
& x_{14}+x_{23}+x_{24}+S_{17}=3 \\
& x_{12}+x_{13}+S_{18}=2 \\
& x_{12}+x_{14}+S_{19}=2 \\
& x_{12}+x_{23}+S_{20}=2 \\
& x_{12}+x_{24}+S_{21}=2 \\
& x_{13}+x_{14}+S_{22}=2 \\
& x_{13}+x_{23}+S_{23}=2 \\
& x_{13}+x_{34}+S_{24}=2 \\
& x_{14}+x_{24}+S_{25}=2 \\
& x_{14}+x_{34}+S_{26}=2 \\
& x_{23}+x_{24}+S_{27}=2 \\
&
\end{aligned}
$$

$$
\begin{aligned}
& x_{23}+x_{34}+S_{28}=2 \\
& x_{24}+x_{34}+S_{29}=2 \\
& x_{12}+S_{30}=1 \\
& x_{13}+S_{31}=1 \\
& x_{14}+S_{32}=1 \\
& x_{23}+S_{33}=1 \\
& x_{24}+S_{34}=1 \\
& x_{34}+S_{35}=1 \\
& x_{12}+x_{13}+x_{14}+x_{23}+ \\
& x_{24}+x_{34}+S_{36}=3 \\
& x_{12}, x_{13}, x_{14}, x_{23}, x_{24}, x_{34} \in\{0,1\}
\end{aligned}
$$

b. Setelah dilakukan metode simpleks ternyata solusi belum berbentuk IP karena masih memuat pecahan sehingga hasilnya tidak layak (infeasible). Oleh karena itu dilakukan proses cutting plane.

Dalam metode simpleks iterasi terakhir, dipilih salah satu variabel-variabel yang berupa pecahan yaitu

$0 x_{12}+0.2 x_{13}+x_{14}+$

$0.6 x_{23}+0.8 x_{24}+1.2 x_{34}+$

$0.2 S_{1}-0.2 S_{8}-0.2 S_{9}=0.5$

Kemudian

nyatakan

persamaan tersebut sebagai penjumlahan dari $\lfloor x\rfloor$ dalam bentuk $\lfloor x\rfloor+f$ dimana $0 \leq f<1 \quad$ dan mengelompokkan nilai yang berupa integer sebelah kiri dan nilai yang berupa pecahan sebelah kanan diperoleh

$0 x_{12}+0 x_{13}+x_{14}+0 x_{23}+$ $0 x_{24}+x_{34}+0 S_{1}-S_{8}-$ $S_{24}-S_{35}-1=0.4-$ $0.2 x_{13}-0.6 x_{23}-0.8 x_{24}-$ $0.2 x_{34}-0.2 S_{1}-0.8 S_{8}-$ $0.8 S_{24}-0.8 S_{35}$

2. Membuat suatu pertidaksamaan dengan cara mengambil ruas kanan lebih kecil sama dengan nol. 
ISSN 2089-8703 (Print) Vol. 7, No. 1 (2018)

ISSN 2442-5419 (Online)

$$
\begin{aligned}
& 0.5-0.2 x_{13}-0.6 x_{23}- \\
& 0.8 x_{24}-0.2 x_{34}-0.2 S_{1}- \\
& 0.8 S_{8}-0.8 S_{24}-0.8 S_{35} \leq 0
\end{aligned}
$$

3. Mengganti nilai-nilai variable Slack $\left(S_{1}, S_{8}, S_{24}, S_{35}\right)$ yang ada pada pertidaksamaan dengan menggunakan kendala awal. Sehingga diperoleh kendala baru yaitu

$x_{12}-0.6 x_{13}+x_{14}+0.8 x_{24}+$ $3.6 x_{34} \leq 12.5$

4. Setelah kendala baru dimasukkan ke dalam kendala awal diperoleh

$$
\begin{array}{lll}
x_{12}=0, & x_{13}=0, & x_{14}= \\
1, & \\
x_{23}=1, & x_{24}=1, & x_{34}= \\
0 &
\end{array}
$$

Hasil cutting plane dari graf $K_{4}$ dapat dilihat seperti pada gambar berikut

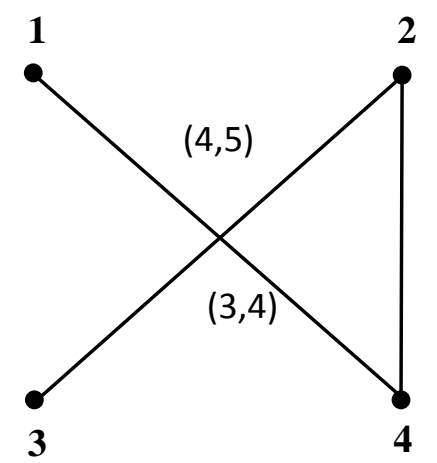

Gambar 3. MST dengan kendala bobot dari graf lengkap $K_{4}$ setelah dilakukan proses cutting plane.

Berikut ini merupakan contoh graf lengkap $K_{4}$ dengan kendala bobot dimana solusinya infeasible (tidak layak).

Diberikan suatu graf lengkap $K_{4}$ dengan kendala bobot, akan dicari MST nya dengan menggunakan metode cutting plane, dengan bobot maksimalnya 100 .

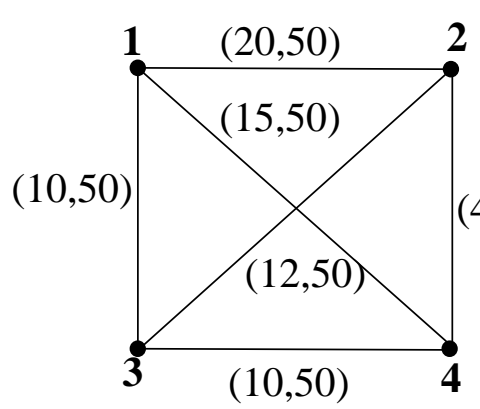

Gambar 4. Graf lengkap $K_{4}$ Fungsi tujuan

$$
\begin{gathered}
\operatorname{Min} Z=20 x_{12}+10 x_{13}+15 x_{14}+ \\
12 x_{23}+45 x_{24}+10 x_{34}
\end{gathered}
$$

dengan kendala

$$
\begin{aligned}
& 50 x_{12}+50 x_{13}+50 x_{14}+50 x_{23}+ \\
& 50 x_{24}+50 x_{34} \leq 100 \\
& x_{12}+x_{13}+x_{14} \leq 3 \\
& x_{12}+x_{13}+x_{24} \leq 3 \\
& x_{12}+x_{13}+x_{34} \leq 3 \\
& x_{12}+x_{14}+x_{34} \leq 3 \\
& x_{12}+x_{23}+x_{24} \leq 3 \\
& x_{12}+x_{23}+x_{34} \leq 3 \\
& x_{12}+x_{24}+x_{34} \leq 3 \\
& x_{13}+x_{14}+x_{24} \leq 3 \\
& x_{13}+x_{23}+x_{24} \leq 3 \\
& x_{13}+x_{23}+x_{34} \leq 3 \\
& x_{13}+x_{24}+x_{34} \leq 3 \\
& x_{14}+x_{23}+x_{34} \leq 3 \\
& x_{14}+x_{24}+x_{34} \leq 3 \\
& x_{12}+x_{14}+x_{23} \leq 3 \\
& x_{13}+x_{14}+x_{23} \leq 3 \\
& x_{14}+x_{23}+x_{24} \leq 3 \\
& x_{12}+x_{13} \leq 2 \\
& x_{12}+x_{14} \leq 2 \\
& x_{12}+x_{23} \leq 2 \\
& x_{12}+x_{24} \leq 2 \\
& x_{13}+x_{14} \leq 2 \\
& x_{13}+x_{24} \leq 2 \\
& x_{13}+x_{34} \leq 2 \\
& x_{14}+x_{24} \leq 2 \\
& x_{14}+x_{34} \leq 2 \\
& x_{23}+x_{24} \leq 2 \\
& x_{23}+x_{34} \leq 2 \\
& x_{24}+x_{34} \leq 2 \\
& x_{12} \leq 1 \\
& x_{13} \leq 1 \\
&
\end{aligned}
$$


$x_{14} \leq 1$

$x_{23} \leq 1$

$x_{24} \leq 1$

$x_{34} \leq 1$

$x_{12}+x_{13}+x_{14}+x_{23}+x_{24}+x_{34}=3$

$x_{12}, x_{13}, x_{14}, x_{23}, x_{24}, x_{34} \in\{0,1\}$

Setelah dicari solusi dengan menggunakan metode cutting plane diperoleh

$x_{12}=0, \quad x_{13}=1, \quad x_{14}=0$,

$x_{23}=0, \quad x_{24}=0, \quad x_{34}=1$

Hasil cutting plane dari graf $K_{4}$ dapat dilihat seperti pada gambar berikut

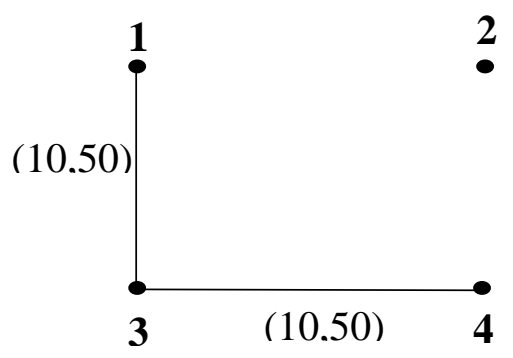

Gambar 5. MST dengan kendala bobot pada graf lengkap $K_{4}$ setelah dilakukan cutting plane

Berdasarkan hasil diatas, graf lengkap $K_{4}$ setelah menggunakan cutting plane tidak membentuk spanning tree karena tidak ada edge yang terhubung pada vertex ke-2 mengakibatkan solusi yang infeasible, sehingga hanya dua edge yang memenuhi batas bobot maksimal. Hal ini disebabkan karena jumlah bobot pada setiap edge melebihi batas bobot maksimal yaitu kurang dari sama dengan 100 (dapat dilihat di kendala awal).

\section{MST dengan Kendala Bobot Pada Graf Lengkap $K_{5}$}

Berikut ini menentukan MST pada graf lengkap $K_{5}$ dengan kendala bobot dan penyelesaiannya menggunakan metode cutting plane, dengan bobot maksimalnya adalah kurang dari sama dengan 36.

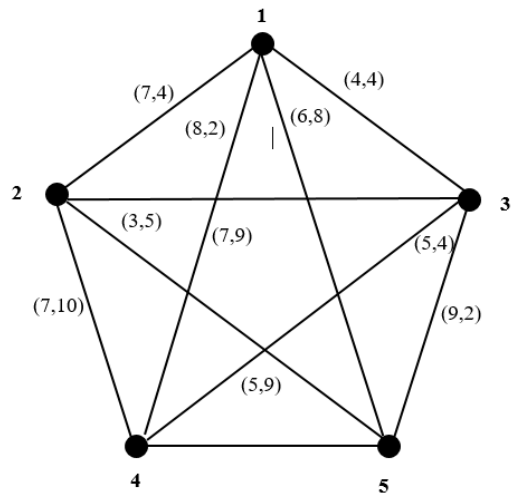

Gambar 6. Graf lengkap $K_{5}$ dengan kendala bobot

Setelah dicari solusinya dengan menggunakan metode cutting plane diperoleh

$$
\begin{aligned}
& x_{13}=1, \quad x_{25}=1, \\
& x_{34}=1, \quad x_{45}=1
\end{aligned}
$$

sehingga MST dari graf lengkap $K_{5}$ adalah sebagai berikut

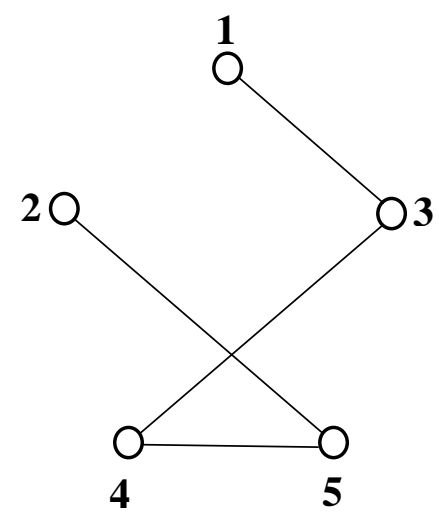

Gambar 7. MST dengan kendala bobot dari graf lengkap $K_{5}$ setelah dilakukan proses cutting plane.

\section{KESIMPULAN DAN SARAN}

Kesimpulan dari hasil dan pembahasan tersebut adalah

1. Dalam menentukan MST pada graf lengkap $K_{4}$ dan $K_{5}$ dengan kendala bobot dapat dapat diselesaikan dengan metode 
cutting plane, dimana bobot pada setiap edge tidak melebihi batas maksimum bobot yang ditentukan. Jika melebihi bobot maksimalnya maka solusinya infeasible,

2. Untuk graf lengkap dengan $n \geq 6$ diperoleh jumlah pertidaksamaannya diatas seribu pertidaksamaan. Pada graf lengkap $\quad K_{n} \quad$ jumlah pertidaksamaannnya yaitu

$$
\begin{aligned}
& 1+C_{n}^{n} * n^{n-2}+C_{n-1}^{n} * \\
& (n-1)^{n-3}+C_{n-2}^{n} * \\
& (n-2)^{n-4}+\cdots+C_{2}^{n}
\end{aligned}
$$

Saran yang dapat disampaikan dari hasil penelitian ini adalah untuk penelitian selanjutnya, menentukan minimum spanning tree dengan kendala bobot dapat digunakan algoritma Prim dan algoritma Kruskal. Jika menggunakan metode penyelesaian IP, maka dapat digunakan metode selain metode cutting plane, yaitu metode-metode eksak.

\section{DAFTAR PUSTAKA}

Bronson, R. 1996. Teori dan Soal-Soal Operation Research. Jakarta: Erlangga.

Deo, N. 1989. Graph Theory with Aplications to Engineering and Computer Science. Prentice Hall, Inc. Englewood Cliffs, New Jersey. Hal. 461.

Henn, T. S. 2007. Weight-Constrained Minimum Spanning Tree Problem. Diploma Thesis: University of Kaiserslautern Departement of Mathematics. Hal 7-25.

Munir, R. 2012. Matematika Diskrit. Bandung: Informatika.

Nurbaiti, Wahyuni. 2015. Aplikasi Minimum Spanning Tree Pada Jaringan Listrik Di Perumahan
Mutiara Indah Village. Jurnal MSA. Vol. 3 No. 1, Hal 47-56.

Siang, J.J. 2009. Matematika Diskrit dan Aplikasinya pada Ilmu Komputer. Yogyakarta: ANDI

Subagyo, P., Asri, M., Handoko, T.H. 2009. Dasar-Dasar Operations Research. Yogyakarta: BPEE.

Wamiliana. 2015. Program Linear Teori dan Terapannya. CV Anugrah Utama Raharja (AURA), Bandar Lampung. 